\title{
Dental complications associated with neonatal intubation in preterm infants
}

\author{
Ik-Hwan Kim, Chung-Min Kang, Je Seon Song, Jae-Ho Lee \\ Department of Pediatric Dentistry, College of Dentistry, Yonsei University, Seoul, Korea
}

\begin{abstract}
This paper describes the potential oral complications in preterm infants who have undergone orotracheal intubation. Neonatal intubation may have adverse effects on the developing deciduous teeth, oral soft tissues, and even the permanent teeth. However, endotracheal intubation may be essential for the survival of premature infants, owing to incomplete tracheal development. Excessive pressure to the oral tissue must be avoided, in cases where orotracheal intubation is inevitable. Moreover, the potential oral complications must be considered when neonatal intubation is performed for the patient's survival, and subsequent reevaluation and proper oral health care are needed.
\end{abstract}

Keywords: Oral complications; Orotracheal Intubation; Premature Infant.

This is an Open Access article distributed under the terms of the Creative Commons Attribution Non-Commercial License (http://creativecommons.org/licenses/by-nc/4.0/) which permits unrestricted non-commercial use, distribution, and reproduction in any medium, provided the original work is properly cited.

\section{INTRODUCTION}

Orofacial trauma that causes injury to the alveolar ridge is extremely rare, prior to the eruption of primary anterior teeth. Orofacial trauma occurs as infants begin to crawl, its incidence rises as infants begin to walk, and peaks at 2-3 years of age when children become increasingly active [1-3]. For these reasons, trauma that occurs prior to the eruption of the primary anterior teeth may definitely have an impact, although it is often neglected as an etiology of the abnormalities of the deciduous dentition [4]. Orotracheal intubation can be one of the most common causes of injury prior to primary tooth eruption.

Several low-weight premature infants require surgery or incubator care, owing to multiple medical problems. They are unprepared for extra-uterine life and have immaturely developed brain, lungs, and eyes [5-6]. Several premature infants need intubation due to incomplete lung development [7], and 1 of 500 newborn babies may need intubation at birth [8].

Endotracheal intubation is a rapid, safe, simple, and non-surgical technique, which is the gold-standard for airway management, since its advantages include promoting airway patency and preventing pulmonary aspiration [9].

However, pharyngeal, esophageal, and tracheal trauma or perforation; intubation of the mainstem bronchus; subglottic stenosis; accidental extubation; post-extubation atelectasis; respiratory infection; erosion of the nares or septum; and injury to the maxillary anterior alveolar ridge and developing tooth germs may occur during the intubation process [10]. Orotracheal tubes used to prevent septal and respiratory impairment caused by a nasotracheal tube, may have an impact on oral tissue develop-

Received: September 26, 2019 - Revised: October 16, 2019 - Accepted: October 21, 2019

Corresponding Author: Jae-Ho Lee, Department of Pediatric Dentistry, Yonsei University College of Dentistry, 250 Seongsanno, Seodaemun-gu, Seoul 120-752, Korea

Tel: +82-2-2228-3173 Fax: +82-2-365-7420 E-mail address:LEEJH@yuhs.ac

Copyright(C) 2019 Journal of Dental Anesthesia and Pain Medicine 
ment $[11,12]$.

Various complications of orotracheal intubation in infants have been documented in the literature (Tables 1 and 2), including acute [13-16] and chronic trauma [17] to the hypopharyngeal structures, systemic [18-20], and local [21] side effects, and deleterious effects on oral development [22-25]. Delayed eruption, ectopic impaction, and tooth malformation following orotracheal intubation are reportedly caused by displacement and localized trauma to the tooth germ [4,26,27]. Moreover, acquired cleft palate, alveolar grooving, palatal grooving, palataldepth and width asymmetry, crossbite, and dental defects may occur as a result of orotracheal intubation [28].

Deformation or enamel defect is a classical dental abnormality of the primary teeth. The mineralization of primary incisors commences at 4 months after birth, and

Table 1. Complications caused by orotracheal intubation during oral development

Alveolar / Palatal grooving

Palatal deformation

Defective development of Enamel(DDE)

Tooth malformation

Displacement of tooth germ

Eruption sequence

Crossbite

Oral commissure defect

TMJ injury

Tongue injury

Incorrect pronunciation crown mineralization is completed at 6 months. On the other hand, mineralization of primary molars commences at the end of 5 months and is completed about 1 year after delivery. Trauma to the region of the developing tooth germ during this period may result in dental anomalies [29]. Enamel hypoplasia is reportedly observed in about $18-80 \%$ of preterm or other medically compromised premature infants, who underwent neonatal intubation [30,31].

Despite medical and dental research on the relationship between orotracheal intubation and developmental changes, it is still difficult to clearly determine whether the impact on orofacial tissues is related to preterm birth or extrinsic factors such as orotracheal intubation [32].

\section{ALVEOLAR AND PALATAL GROOVES}

Among the preterm infants, who underwent orotracheal intubation, $23.1 \%$ showed changes in the alveolar contour [32]. Erenberg and Nowak [24] reported the association between a higher incidence of palatal grooving and neonatal intubation. According to Boice et al. [38], a prominent concavity was observed on the left maxillary alveolar ridge in non-surviving low birth-weight infants, who underwent orotracheal intubation. Moreover, severe

Table 2. Type of complications and their incidence

\begin{tabular}{|c|c|c|c|c|}
\hline Complication & $\begin{array}{l}\text { Author } \\
\text { (Year) }\end{array}$ & $\begin{array}{l}\text { No. patient } \\
\text { (Intubated) }\end{array}$ & Intubation periods & Incidences \\
\hline \multirow[t]{3}{*}{ Palatal Grooving } & $\begin{array}{l}\text { Alves } \\
\text { (2012)[32] }\end{array}$ & 66 & & $36.4 \%$ \\
\hline & $\begin{array}{l}\text { Erenberg } \\
(1984)[24]\end{array}$ & 63 & $\begin{array}{l}1 \text { to } 62 \text { days } \\
\text { (> } 2 \text { weeks) }\end{array}$ & $\begin{array}{l}47.6 \% \\
(87.5 \%)\end{array}$ \\
\hline & $\begin{array}{l}\text { Wetzel } \\
\text { (1980)[33] }\end{array}$ & 5 & & \\
\hline \multirow[t]{2}{*}{$\mathrm{DDE}$} & $\begin{array}{l}\text { Suely } \\
(2014)[34]\end{array}$ & 77 & & $57 \%$ \\
\hline & $\begin{array}{l}\text { Seow } \\
(1984)[35]\end{array}$ & 40 & & $85 \%$ \\
\hline \multirow[t]{3}{*}{ Palatal Deformation } & $\begin{array}{l}\text { Procter } \\
\text { (1998)[36] }\end{array}$ & 23 & 1 to 32 days & \\
\hline & $\begin{array}{l}\text { Alves } \\
\text { (2012)[32] }\end{array}$ & 66 & & $16.7 \%$ \\
\hline & $\begin{array}{l}\text { Costa } \\
\text { (2017)[37] }\end{array}$ & 34 & $>7$ days & $67.6 \%$ \\
\hline
\end{tabular}


developmental defects of the enamel organ were observed in this area.

In another study, indentation of the anterior ridge was observed in infants who were mechanically ventilated following intubation, due to continuous force exerted by the tube $[33,39]$.

Intraoral protective devices have been used with orotracheal intubation tubes, to prevent alveolar or palatal deformation caused by intubation. [40,41] These appliances were designed to protect the oral tissue from pressure exerted by the tube [42,43]. Fadavi et al. [44] performed a randomized prospective study with 26 infants who had undergone orotracheal intubation from day 7 to 109 of birth, with birth weights of 540-1,470 g. While the control group showed 2-5-mm palatal grooves, preterm infants in whom a protective device was used did not exhibit palatal grooves.

\section{DEFECTIVE DEVELOPMENT OF ENAMEL}

Defective development of enamel (DDE) may manifest as a defective area on the enamel surface or an incompletely formed crown (Fig. 1).

Compared to premature infants who had not undergone intubation, DDE was 6 times more prevalent among premature infants who underwent orotracheal intubation. Of 157 premature infants, 77 infants underwent intubation and 80 did not. Fifty-one infants exhibited DDE, 44 of whom were intubated. while 7 had not undergone intubation. Of the 77 intubated infants, 44 (57\%) showed DDE, and 7 (9\%) of 80 non-intubated infants exhibited DDE. Furthermore, a total of 177 teeth with DDE were observed in 51 infants, which was markedly more common in the maxilla $(80.2 \%)$ than in the mandible (19.8\%) [34].

Another study reported that defects in maxillary incisors were observed in $85 \%$ of intubated infants. The mean birth weight of 63 low-weight infants was 1154 $\mathrm{g}$, with a range from $605 \mathrm{~g}-1500 \mathrm{~g}$. Of these, 40 infants underwent endotracheal intubation, and 34 (85\%) had

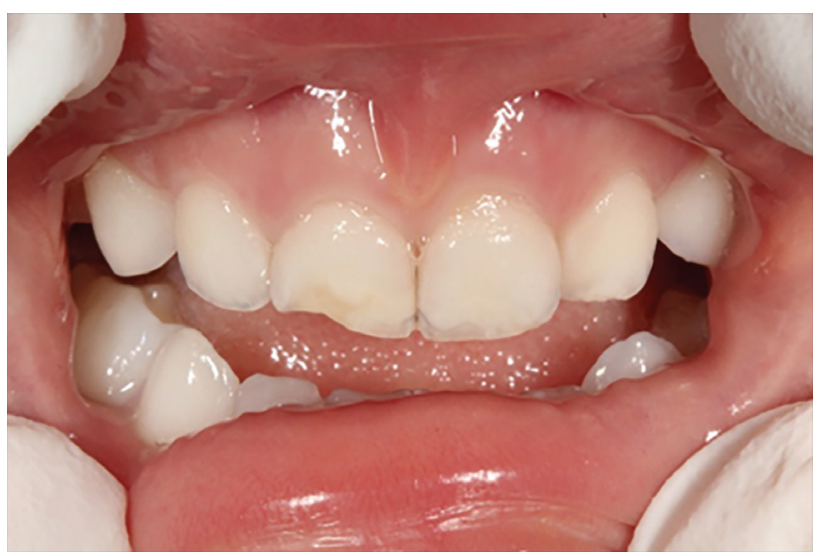

Fig. 1. Photograph depicting defective development of enamel in the primary maxillary right central incisor with a yellowish lesion.

enamel defects in the maxillary anterior teeth. Of the 23 non-intubated infants, only $5(21.7 \%)$ showed DDE in the maxillary anterior teeth [35].

\section{TOOTH MALFORMATION}

A patient underwent multiple orotracheal intubations for six rounds of surgery, starting from 9 days to 4 years of age, due to a complex cardiac abnormality. The patient's primary maxillary right central incisor had not erupted till 3 years of age, and the contralateral primary incisor did not erupt till 6 years and 10 months of age. In addition to delayed eruption, the maxillary deciduous incisor exhibited abnormal morphology, enamel hypoplasia, and abnormal dentine formation [27].

A 2-year-old girl visited the clinic with a chief complaint of an unerupted primary maxillary left incisor. The patient born prematurely at a gestational age of 25 weeks and 6 days, with a birth weight of $830 \mathrm{~g}$. She had undergone orotracheal intubation and was placed in an incubator for about 5 months, due to neonatal respiratory distress syndrome. Clinical examination revealed that the primary maxillary left lateral incisor and canine had not erupted, and radiography revealed malformation, delayed eruption, and dilacerations of the roots of the corresponding teeth (Fig. 2, 3). During a periodic follow-up, no spontaneous pain and clinical abnormalities were 


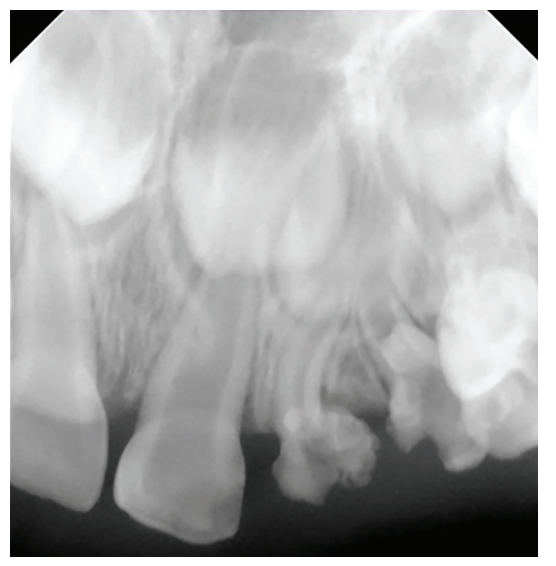

Fig. 2. Radiograph depicting malformation of the primary maxillary left lateral incisor and canine.

observed in the malformed teeth. No abnormal findings were observed in the developing permanent teeth [45].

A 16-month-old boy visited the clinic with a chief complaint of an erupted maxillary primary incisor with an abnormal morphology. The patient was born prematurely, at a gestational age of 25 weeks and 4 days, with a birth weight of $880 \mathrm{~g}$. Orotracheal intubation was maintained for about 2 months, with 3 months of incubator care, due to bronchopulmonary dysplasia and neonatal respiratory distress syndrome. Clinical examination revealed delayed eruption of the primary maxillary left lateral incisor and canine, and radiography revealed malformation of the same teeth (Fig. 2, 3) [45].

\section{DISPLACEMENT OF THE TOOTH GERM}

A 16-month-old girl visited the clinic with a chief complaint of delayed eruption of a deciduous incisor. The patient was born prematurely, at a gestational age of 24 weeks, with a birth weight of $480 \mathrm{~g}$. She had undergone patent ductus arteriosus surgery at 1 month of age, and surgery under general anesthesia at 4 months of age, for hernia and retinal detachment and at 8 months for another retinal detachment. Oral examination revealed that the maxillary right primary incisor and mandibular incisor were erupted, but the maxillary left primary incisor was unerupted. No abnormal findings were observed with the

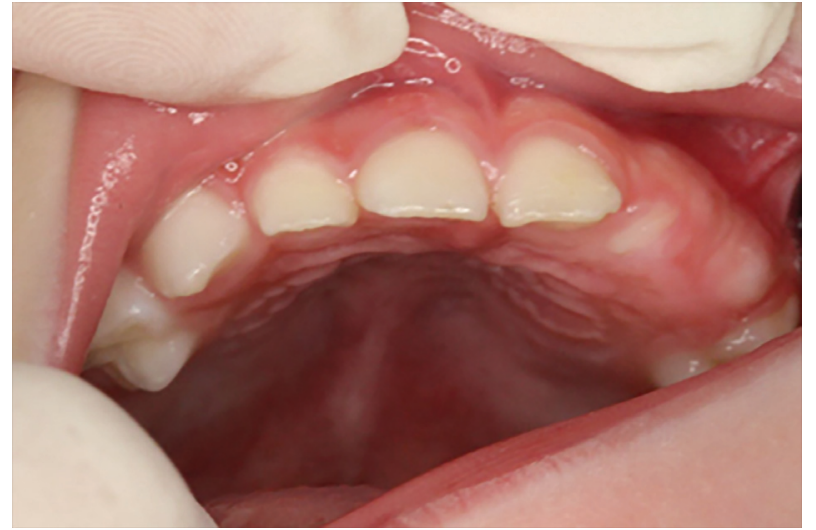

Fig. 3. Photograph depicting delayed eruption of the primary maxillary left lateral incisor and canine.

erupted primary tooth, and radiography revealed suspected maxillary primary left central incisor malformation and primary central and lateral incisor displacement. Computed tomography (CT) was performed under sedation during the periodic follow-up two months later, with the caregiver's consent. CT revealed displacement of the maxillary left primary central, lateral incisor, and canine tooth germs, with malformation of the primary left incisor. The patient had no systemic disease associated with delayed eruption, and only had a history of multiple orotracheal intubations prior to the eruption of the primary anterior teeth, due to various medical issues related to premature birth. Furthermore, considering that the delayed eruption, malformation, and displacement of tooth germs were localized to the left maxilla, these findings can probably be attributed to a local factor. [46]

Although the displacement of a dental follicle cannot be detected during clinical examination, it is often accompanied ectopic or delayed eruption.

\section{PALATAL SHAPE}

Deformation may be caused by the application of unbalanced and continuous mechanical forces to malleable tissues [36]. During the early stage of development of the oral cavity, the palatal bone is malleable and is easily influenced by extrinsic force [47]. Deformation of the median palatine suture may occur due to prolonged 


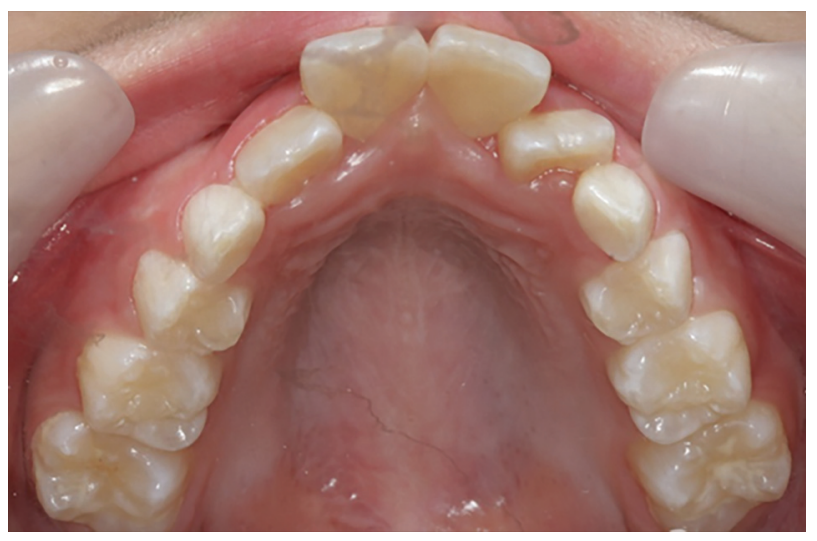

Fig. 4. Photograph depicting a narrow palate.

orotracheal intubation, since the endotracheal tube exerts continuous pressure on the palate $[36,37,48,49]$.

Neonatal intubation lasting for more than 10 days has been reported to induce palatal deformation in infants. This is thought to be a result of direct pressure caused to the median palatine suture by the orotracheal tube [36]; $12 \%$ of preterm infants who underwent neonatal intubation exhibited palatal deformation [32].

Another study on the effects of orotracheal intubation on the palatal architecture in preterm infants classified the palatal shape of neonates into square, narrow, and ovoid. A narrow palate $(67.6 \%)$ was more frequently observed than the square $(14.7 \%)$ or ovoid $(17.7 \%)$ morphology in neonates who had undergone intubation for 7 days or longer [37]. The narrow palatal morphology is maintained even after the patient has fully grown (Fig. 4).

Ash et al. [40] assessed the effect of using protective palate plates in preterm infants. They investigated 15 non-intubated infants (control group) and 30 intubated infants born before 32 weeks of gestation, in whom intubation was maintained for at least 10 days and the use of palate plate was randomly controlled. Compared to the non-intubated infants, infants in whom the palatal plate was not used, had a smaller, deeper, and narrower palate. When the plate was used, a reduction of the narrowing and depth of palate was observed in the intubated infants. Palatal plates did not interfere with the lateral growth of the infant's palate or harm other oral tissues.

\section{ACQUIRED ORAL COMMISSURE DEFECT}

An oral commissure defect caused by prolonged endotracheal intubation is rarely reported. Infants born at 23 weeks of gestation underwent neonatal intubation after birth for mechanical ventilation and had histories of respiratory distress syndrome, sepsis, pneumonia, patent ductus arteriosus, tracheitis, anemia, thrombocytopenia, inguinal hernia, and chronic pneumatocele. On day 72 after a $3.5-\mathrm{mm}$ endotracheal tube (ETT) intubation, a circular lesion was discovered on the left side of the mouth while replacing the ETT holder. The lesion, which occurred in the oral commissure area, was clean and smooth, without active bleeding, with minimal reactive inflammation [22].

\section{TEMPOROMANDIBULAR JOINT INJURY}

Temporomandibular joint (TMJ) injury is very rare but severe. Increased force may cause a rupture of the lateral ligament, while locating the glottis during laryngoscopy. This can reportedly lead to limited mouth opening, joint pain, lateral deviation of the mandible, and protrusion of the mandible [9].

\section{TONGUE INJURY}

Compression due to prolonged endotracheal intubation may induce ischemia or venous congestion and ultimately cause macroglossia. Obstruction of the submandibular duct by the ETT may lead to massive tongue swelling. Furthermore, compression injury inflicted during the intubation process has been reported to cause lingual nerve injury $[9,27]$. Transient tongue weakness, numbness, or paralysis following laryngoscopy may cause compression of the hypoglossal nerves [50]. In addition to 
transient tongue damage, cases of uvula injury, sore throat, odynophagia, coughing, and serious life-threatening airway obstruction have also been reported [51].

\section{SIMULTANEOUS OCCURRENCES}

As described in this paper, orotracheal intubation in preterm infants can have complex effects as opposed to a single effect on oral tissue development. According to the study by Alves et al. [32], alveolar contour was strongly associated with crossbite and eruption sequence, while palatal form and crown color showed a statistically significant correlation. Kopra and Davis reported that intubated children frequently exhibited a high palatal vault, palatal grooves, and posterior crossbite compared to the non-intubated control group, and such complex oral abnormalities may induce speech impairments [28].

\section{REASONS FOR LEFT MAXILLARY PREDILECTION}

The reason for the localization of injuries to the developing left maxillary primary anterior teeth may be explained by the endotracheal intubation and laryngoscope process. In an ideal examination process, no abnormal force should be applied during intubation and laryngoscopy, which may affect the anterior alveolar bone. However, inadvertent force may be applied to the left maxillary alveolar bone, while manipulating the device in low-birth weight infants. Moreover, the developing tooth germ may be more sensitive to external stimulation in very low-birth weight infants, because the cortical bone is thinner due to osteopenia [35]. According to a previous report, 86 out of 142 maxillary primary teeth with DDE were primary left incisors (61\%), which implies that DDE has a predilection for the left side [34]. Another study also reported 44 maxillary anterior teeth with defects in 40 intubated children, of which 13 teeth $(30 \%)$ were primary right incisors, while $31(70 \%)$ were primary left incisors [35].

\section{CONCLUSION}

Although this study discussed the adverse effects of endotracheal intubation on oral development, intubation is essential for the survival of preterm infants. Protective devices have been developed to decrease the side-effects of intubation. However, impression making prior to orotracheal intubation may be difficult and the use of protective appliances may be restricted depending on the medical situation.

Orotracheal intubation tubes may cause dental malformation, enamel defects, displacement of the tooth germ, delayed eruption, and oral tissue development, and it may affect the permanent and primary dentitions. Therefore, periodic follow-ups are essential for reevaluation and comprehensive treatment planning, and dentists are responsible for actively intervening in this process and guiding guardians about the child's oral health care needs.

\section{AUHHOR ORCIDS}

Ik-Hwan Kim: https://orcid.org/0000-0003-4444-532X

Chung-Min Kang: https://orcid.org/0000-0001-7813-3741

Je Seon Song: https://orcid.org/0000-0001-8620-5629

Jae-Ho Lee: https://orcid.org/0000-0002-1556-3485

DECLARATION OF INTEREST: The authors had no conflicts of interest to declare.

\section{REFERENCES}

1. Gabris K, Tarjan I, Rozsa N. Dental trauma in children presenting for treatment at the Department of Dentistry for Children and Orthodontics, Budapest, 1985-1999. Dent Traumatol 2001; 17: 103-8.

2. Hamilton FA, Hill FJ, Holloway PJ. An investigation of dento-alveolar trauma and its treatment in an adolescent population. Part 1: The prevalence and incidence of injuries and the extent and adequacy of treatment received. Br 
Dent J 1997; 182: 91-5.

3. Petti S, Tarsitani G. Traumatic injuries to anterior teeth in Italian schoolchildren: prevalence and risk factors. Endod Dent Traumatol 1996; 12: 294-7.

4. Uzamis M, Olmez S, Er N. Unusual impaction of inverted primary incisor: report of case. ASDC J Dent Child 2001; 68: 67-9, 32.

5. Shin SM, Chang YP, Lee ES, Lee YA, Son DW, Kim $\mathrm{MH}$, et al. Low birth weight, very low birth weight, very low birth weight rates of newborn infants in Korea. J Korean Soc Neonatol 2005; 12: 233-7.

6. Usher RH. The special problems of the premature infant. In: Neonatology : Pathophysiology and Management of the Newborn. 2nd ed. Lippincott Williams and Wilkins. 1981, pp 230-61.

7. Rennie JM, Kendall G. A Manual of Neonatal Intensive Care. 5th ed. CRC Press. 2013.

8. Palme-Kilander C. Methods of resuscitation in lowApgar-score newborn infants--a national survey. Acta Paediatr 1992; 81: 739-44.

9. Chinnappa A, Ambareen Z. Dental complications of intubation in pediatric patients and its management. Int J Dent Sci Res 2014; 2: 9-11.

10. Wyllie JP. Neonatal endotracheal intubation. Arch Dis Child Educ Pract Ed 2008; 93: 44-9.

11. Jung AL, Thomas GK. Stricture of the nasal vestibule: a complication of nasotracheal intubation in newborn infants. J Pediatr 1974; 85: 412-4.

12. Eastman DL. Dental outcomes of preterm infants. Newborn Infant Nurs Rev 2003; 3: 93-8.

13. Lagoo JY, Jose J, Kilpadi KA. Tracheal perforation in a neonate: A devastating complication following traumatic endotracheal intubation. Indian J Anaesth 2013; 57: 623-4.

14. Mollitt DL, Schullinger JN, Santulli TV. Selective management of iatrogenic esophageal perforation in the newborn. J Pediatr Surg 1981; 16: 989-93.

15. Joshi VV, Mandavia SG, Stern L, Wiglesworth FW. Acute lesions induced by endotracheal intubation. Occurrence in the upper respiratory tract of newborn infants with respiratory distress syndrome. Am J Dis Child 1972; 124: 646-9.
16. Fan LL, Flynn JW, Pathak DR. Risk factors predicting laryngeal injury in intubated neonates. Crit Care Med 1983; 11: 431-3.

17. Jones R, Bodnar A, Roan Y, Johnson D. Subglottic stenosis in newborn intensive care unit graduates. Am J Dis Child 1981; 135: 367-8.

18. Harris H, Wirtschafter D, Cassady G. Endotracheal intubation and its relationship to bacterial colonization and systemic infection of newborn infants. Pediatrics 1976; 58: 816-23.

19. Browning DH, Graves SA. Incidence of aspiration with endotracheal tubes in children. J Pediatr 1983; 102: 582-4.

20. Marshall TA, Deeder R, Pai S, Berkowitz GP, Austin TL. Physiologic changes associated with endotracheal intubation in preterm infants. Crit Care Med 1984; 12: 501-3.

21. Redding GJ, Fan L, Cotton EK, Brooks JG. Partial obstruction of endotracheal tubes in children: incidence, etiology, significance. Crit Care Med 1979; 7: 227-31.

22. Kahn DJ, Spinazzola R. Acquired oral commissure defect: a complication of prolonged endotracheal intubation. $\mathrm{J}$ Perinatol 2005; 25: 612-4.

23. Molteni RA, Bumstead DH. Development and severity of palatal grooves in orally intubated newborns. Effect of 'soft' endotracheal tubes. Am J Dis Child 1986; 140: 357-9.

24. Erenberg A, Nowak AJ. Palatal groove formation in neonates and infants with orotracheal tubes. Am J Dis Child 1984; 138: 974-5.

25. Macey-Dare LV, Moles DR, Evans RD, Nixon F. Long-term effect of neonatal endotracheal intubation on palatal form and symmetry in 8-11-year-old children. Eur J Orthod 1999; 21: 703-10.

26. Seow WK. Effects of preterm birth on oral growth and development. Aust Dent J 1997; 42: 85-91.

27. Mason C, Odell EW, Longhurst P. Dental complications associated with repeated orotracheal intubation in infancy: a case report. Int J Paediatr Dent 1994; 4: 257-64.

28. Kopra DE, Davis EL. Prevalence of oral defects among neonatally intubated 3- to 5- and 7- to 10-year old children. Pediatr Dent 1991; 13: 349-55.

29. Andreasen JO. Traumatic injuries of the teeth. 2nd ed. 
Munksgaard. 1981.

30. Seow WK, Masel JP, Weir C, Tudehope DI. Mineral deficiency in the pathogenesis of enamel hypoplasia in prematurely born, very low birthweight children. Pediatr Dent 1989; 11: 297-302.

31. Seow WK, Humphrys C, Tudehope DI. Increased prevalence of developmental dental defects in low birth-weight, prematurely born children: a controlled study. Pediatr Dent 1987; 9: 221-5.

32. Alves PV, Luiz RR. The influence of orotracheal intubation on the oral tissue development in preterm infants. Oral Health Prev Dent 2012; 10: 141-7.

33. Wetzel RC. Defective dentition following mechanical ventilation. J Pediatr 1980; 97: 334.

34. Suely Falcao de Oliveira Melo N, Guimaraes Vieira Cavalcante da Silva RP, Adilson Soares de Lima A. The neonatal intubation causes defects in primary teeth of premature infants. Biomed Pap Med Fac Univ Palacky Olomouc Czech Repub 2014; 158: 605-12.

35. Seow WK, Brown JP, Tudehope DI, O'Callaghan M. Developmental defects in the primary dentition of low birth-weight infants: adverse effects of laryngoscopy and prolonged endotracheal intubation. Pediatr Dent 1984; 6: 28-31.

36. Procter AM, Lether D, Oliver RG, Cartlidge PH. Deformation of the palate in preterm infants. Arch Dis Child Fetal Neonatal Ed 1998; 78: F29-32.

37. da Costa SC, dos Santos MTBR, de Carvalho WB, Miyazato DG, Ceccon MEJR, de Albuquerque Diniz EM. Influence of orotracheal intubation on preterm infant palate shape between 12 and 24 months old. J Oral Diag 2017; 2: 1-5.

38. Boice JB, Krous HF, Foley JM. Gingival and dental complications of orotracheal intubation. JAMA 1976; 236: 957-8.

39. Wetzel RC. Defective dentition following mechanical ventilation. J Pediatr 1980; 97: 334.

40. Ash SP, Moss JP. An investigation of the features of the pre-term infant palate and the effect of prolonged orotracheal intubation with and without protective appliances. Bri J Orthod 1987; 14: 253-61.

41. Claure N, Bancalari E. Automated respiratory support in newborn infants. Semin Fetal Neonatal Med 2009; 14: $35-41$.

42. Erenberg A, Nowak AJ. Appliance for stabilizing orogastric and orotracheal tubes in infants. Crit Care Med 1984; 12: 669-71.

43. von Gonten AS, Meyer JB Jr., Kim AK. Dental management of neonates requiring prolonged oral intubation. J Prosthodont 1995; 4: 221-5.

44. Fadavi S, Adeni S, Dziedzic K, Punwani I, Vidyasagar D. Use of a palatal stabilizing device in prevention of palatal grooves in premature infants. Crit Care Med 1990; 18: $1279-81$.

45. Lim SY, Kim SO, Lee JH, Kim IH. Developmental disturbance of primary incisors in preterm infants with endotracheal intubation : A case report. J Korean Dis Oral Health 2019; 15: 89-93.

46. Shin YK, Hyun HK, Kim YJ, Kim JW, Jang KT, Lee $\mathrm{SH}$, et al. Effect of intubation on the primary dentition prior to tooth eruption: A case report. J Korean Acad Pediatr Dent 2008; 35: 504-8.

47. Hohoff A, Rabe H, Ehmer U, Harms E. Palatal development of preterm and low birthweight infants compared to term infants - What do we know? Part 1: The palate of the term newborn. Head Face Med 2005; 1: 8.

48. Biskinis EK, Herz M. Acquired palatal groove after prolonged orotracheal intubation. J Pediatr 1978; 92: 512-3.

49. Duke PM, Coulson JD, Santos JI, Johnson JD. Cleft palate associated with prolonged orotracheal intubation in infancy. J Pediatr 1976; 89: 990-1.

50. Huehns TY, Yentis SM, Cumberworth V. Apparent massive tongue swelling. A complication of orotracheal intubation on the Intensive Care Unit. Anaesthesia 1994; 49: 414-6.

51. Monroe MC, Gravenstein N, Saga-Rumley S. Postoperative sore throat: effect of oropharyngeal airway in orotracheally intubated patients. Anesth Analg 1990; 70: 512-6. 